\title{
Ontario Geriatric Specialist Physician Resources 2018
}

\author{
Michael Borrie, BSc, MB ChB, FRCPC ${ }^{1}$, Tracy Cooper $^{2}$, Monisha Basu, BHSc, MD(c) ${ }^{3}$, \\ Kelly Kay, MA, PhD(c) ${ }^{4}$, Jeanette C. Prorok, PhD, $\mathrm{MSc}^{5}$, Dallas Seitz, MD, $\mathrm{PhD}^{6}$ \\ ${ }^{1}$ Division of Geriatric Medicine, Schulich School of Medicine \& Dentistry, Western University, London, ON; \\ ${ }^{2}$ Division of Geriatric Medicine, Parkwood Institute, St. Josephs Health Care, London, ON; ${ }^{3}$ Faculty of Medicine, \\ University of Toronto, Toronto, ON; ${ }^{4}$ Provincial Geriatrics Leadership Office, Regional Geriatric Programs of \\ Ontario (RGPO); ${ }^{5}$ Research and Knowledge Translation, Canadian Frailty Network, Kingston, ON; ${ }^{6}$ Departments \\ of Psychiatry and Community Health Sciences, Cumming School of Medicine, University of Calgary, Calgary, AB
}

https://doi.org/10.5770/cgj.23.448

\section{ABSTRACT}

\section{Background}

The number of older adults with complex health needs in Ontario is growing. The Ministry of Health and Long-Term Care requested a resource mapping project to assess the current 2018 and projected 2025 number of specialist physician resources.

\section{Methods}

Geriatric specialist physicians were defined as geriatricians, geriatric psychiatrists, and Care of the Elderly (COE) physicians. We determined the current number of geriatricians, geriatric psychiatrists, and COEs and clinical full-time-equivalent complement (CFTE) for geriatric medicine and geriatric psychiatry specialists. We projected the number of new trainees expected to enter practice and the number of physicians expected to retire by 2025 . We compared these numbers and projections against established specialist/population ratios for geriatricians and geriatric psychiatrists.

\section{Results}

There was a deficit of geriatricians and geriatric psychiatrists (geriatricians: CFTE deficit of 150.5; geriatric psychiatrists: CFTE deficit of 116.3). In 2025, the projected CFTE deficit of geriatricians will increase to at least 210.35 and geriatric psychiatrists to 194.6. Only about $30 \%$ of COE physicians work in direct support of specialized services for the elderly.

\section{Conclusions}

There is significant current and anticipated undersupply in the required number of geriatricians, geriatric psychiatrists, and $\mathrm{COE}$ physicians to meet anticipated population demand.

Key words: geriatricians, care of the elderly physicians, physician human resources, specialized geriatric services, Ontario

\section{INTRODUCTION}

\section{Background Provincial Geriatrics Leadership Office Project (PGLO)}

In 2018, the Ministry of Health (MOH) asked the newly developed Provincial Geriatrics Leadership Office (PGLO) to identify and map the various programs, services, and human resources that deliver specialty health-care services to older people living with complex health concerns across Ontario. Under the management of the PGLO leadership, we were tasked with the specialist physician human resource mapping portion of the project. ${ }^{(1)}$

\section{Background}

Over the next 20 years, Canada's population of older adults over the age of 65 is expected to increase by almost $70 \%{ }^{(2)}$

Ontario, like all provincial jurisdictions in Canada, faces growth in the numbers of older adults over 65 with complex health needs. The number of frail older adults is projected to increase to one million by the year 2029.(3) To address this increase, there is a critical need to expand Specialized Geriatric Services (SGS) (including Specialized Geriatric Medicine and Specialized Mental Health Services (SMH)).

In Ontario, SGS provide direct clinical care, programmatic support, education, and knowledge transfer to ensure optimal care for the most vulnerable Ontarians. SGS work in collaboration with general primary care, hospitals, home care, community service agencies, and the long-term care sector. SGS share the current policy focus on reducing care delivered in unconventional places due to demand (e.g., hospital hallways), and work directly to decrease repeat emergency department visits, hospital readmissions, and prolonged or permanent institutionalization among older people. ${ }^{(3)}$ Older people with frailty are at higher risk for hospitalization. ${ }^{(4)}$ Further, people living with dementia are at risk for emergency room use, hospital admission, delirium, and longer hospital 
stays, and they account for a third of Alternate Level of Care (ALC) designation in Canada and contribute to the phenomenon of Hallway Medicine. ${ }^{(5)}$

Physician health human resource planning, including physicians specializing in care of older adults such as geriatric medicine specialists, geriatric psychiatrists, and family physicians with care of the elderly designation (COEs), are of particular relevance in planning for the care of complex older adults. Interdisciplinary teams, inclusive of medical specialties (such as those found within SGS) can significantly improve access to care for Ontario's population of older adults who require specialized care. ${ }^{(6,7,8)}$ Specialized Geriatric Services are defined as a comprehensive, coordinated system of hospital and community-based health services that assess, diagnose, and treat older adults with complex health conditions. These services are provided by interdisciplinary teams with expertise in care of older adults, who work across the continuum of care. SGS are inclusive of both geriatric medicine and geriatric psychiatry services.

\section{Purpose}

This Physician Human Resource Project was intended to produce current state (2018) and projected state (2025) views of geriatric specialist physician resources across the province of Ontario.

One goal was to identify how many geriatricians, geriatric psychiatrists, and COE physicians were working within SGS in each of the 14 Local Health Integration Networks (LHINs). We also compared that number against established specialist/ population ratios for geriatricians and geriatric psychiatrists to identify physician human resource deficits. ${ }^{(9,10)}$ Given the focus on older adults living with complexity and frailty as a population of interest in Ontario health system planning, we anticipate this work will assist communities to understand their present physician human resource supply, facilitate geriatric clinical services planning, and support recruitment.

\section{METHODS}

Our methodology drew on an approach used in an earlier study to determine the number of geriatricians and $\mathrm{COE}$ physicians by province in Canada. ${ }^{(11)}$ We selected a ratio of specialists per 10,000 (population over 65 years) as our method for determining physician human resource requirements. ${ }^{(10)}$ The ratio used is a proxy for the anticipated requirement for specialized support by people over the age of 65 . It allows an approximate comparison of the availability of geriatric specialists by region, and between regions, over time. A ratio does not inform the extent of the needs, such as the burden of comorbid illness, frailty, or mental health and/or substance use concerns, which may differ among older adults between regions. It also does not inform the different ways specialists are working directly or indirectly to address the population need within regions.

We also estimated the future physician complement by calculating the anticipated population need by 2025 using the same established ratio of specialists/10,000 population over 65 years. We calculated the anticipated numbers of newly trained geriatricians, geriatric psychiatrists, and COE physicians who might begin practice in Ontario between 2018 and 2025, using the numbers of trainees completing specialist training per year in current residency programs. ${ }^{(11,12)}$

\section{Full Time/Part Time Status}

A numerical count of specialists alone does not reflect the proportion of their time made available for clinical roles. Physician full-time/part-time status in Canada is commonly defined by the number of half days worked within a five-day work week. A half-day is therefore 0.1 full-time equivalent (FTE), and a physician working five half-days is considered $0.5 \mathrm{FTE}$. For this project, we equated $1.0 \mathrm{FTE}$ as a physician who usually works ten half-days Monday-Friday. We did not include any assumptions about time spent beyond 1.0 FTE. In the six Medical School Centres/Academic Health Science Centres (AHSCs) in Ontario (Hamilton, Kingston, London, Ottawa, Sudbury/Thunder Bay, and Toronto), fulltime geriatricians and geriatric psychiatrists within or external to their Departments or Divisions of Geriatric Medicine and Geriatric Psychiatry are engaged in and support each other to deliver various non-clinical academic roles including formal teaching, curriculum development, quality improvement, research, leadership and administration. For those with academic or leadership roles greater than 20\% FTE, we reduced their Clinical FTE (CFTE) contribution by the percentage of time spent in these roles. In general, because of the multiple roles filled by specialists in AHSCs, CFTEs are lower than in the community. In contrast, community-based specialists are primarily engaged in clinical roles. Although some community-based specialists have leadership or administrative roles, the majority focus on providing direct and indirect clinical consultation for older adults living with complex health concerns.

We assumed $40 \%$ of new graduating specialist trainees in geriatric medicine and geriatric psychiatry might remain in Ontario because a) $38 \%$ of the Canadian population lives in Ontario, b) $42 \%$ of geriatricians already practice in Ontario, and c) $40 \%$ of geriatric trainees trained in Ontario. ${ }^{(12,13,14)}$ To estimate retirements, we assumed, on average, a specialist might retire 40 years after attaining their medical degree. For each specialist, we calculated their potential retirement year by adding 40 years to the date they attained their medical degree, using registration data from the College of Physicians and Surgeons of Ontario (CPSO).

We did not attempt to estimate how many established geriatric specialists might leave the province or be recruited to the province from elsewhere in Canada, or the number of foreign-trained geriatric specialists who might be recruited from the U.S. or overseas between 2018 and 2025.

\section{Geriatric Medicine Specialists}

Geriatric medicine specialists, referred to here as geriatricians, are internal medicine specialists who hold a subspecialty in 
geriatric medicine and are registered to practise in Ontario. They include those who hold Royal College of Physicians and Surgeons of Canada (RCPSC) certification, or those who trained overseas and have the designation as a College of Physicians and Surgeons of Ontario (CPSO) Recognized Specialist in Geriatrics.

\section{Identification of Geriatricians in Ontario}

The publicly available CPSO website ${ }^{(14)}$ was the primary source for the initial list of physicians with a specialization in Geriatric Medicine in Ontario. From the CPSO website, the primary office practice postal code locations were determined and aligned with the respective Local Health Integration Network (LHIN), the geographic division of the health services in place in Ontario from 2006 to 2019. ${ }^{(15)}$

We corresponded by email with the Division Chairs of Geriatric Medicine of Ontario's six Medical Schools/AHSCs, lead community geriatricians, and LHIN/ SGS administrators to confirm the accuracy of the lists. They confirmed the fulltime/part-time status, if known, of the geriatricians working in AHSCs, urban, rural, or remote communities.

Follow-up emails and phone calls were necessary with geriatrician offices/administration staff to confirm their fulltime/part-time status. The CFTE counts were adjusted for the proportion of time spent by geriatricians in academic and leadership roles.

We calculated the number of geriatricians required in the LHIN, using the ratio of 1.175 geriatricians per 10,000 aged 65 and over and the 2016 census population data, and compared it to the actual number of geriatricians and the CFTE complement we collected in 2018. ${ }^{(9)}$

To calculate the number of geriatricians required in each LHIN in 2025, we applied the same ratio to the projected 2025 population over 65 years of each LHIN. ${ }^{(16,17)}$

We determined the number of Geriatric Medicine trainees (average of postgraduate year 5 (PGY-5), 2014-2018), who graduated from the fifth year of residency at 27.5 new trainees in Canada per year, using the Canadian Post-M.D. Education Registry Census. ${ }^{(12)}$ We assumed that $40 \%$ or 11 of these trainees per year between 2018-2025 (8 years) might practice in Ontario, for a total of 88 in the province. From the 2018 number of geriatricians in each LHIN, we subtracted the estimated number of retirements between 2018 and 2025 to arrive at an approximate total geriatrician complement by 2025 .

\section{Geriatric Psychiatrists}

The Royal College first approved examinations for geriatric psychiatry in 2012 and many general psychiatrists who were already practising in geriatric psychiatry prior to 2012 were not required to complete the new Royal College examinations. All registered psychiatrists who are practising in geriatric psychiatry programs, regardless of Royal College of Physicians and Surgeons of Canada subspecialty exam status, were included and, for the purposes of this project, considered geriatric psychiatrists.

\section{Methodology Geriatric Psychiatrists}

Different methods were required to determine the number of geriatric psychiatrists in Ontario. The CPSO does not maintain a register that designates the subspecialty of geriatric psychiatry and thus, geriatric psychiatrists are listed as general psychiatrists on the CPSO website. While the CPSO does not identify the geriatric psychiatry designation, publicly available information with the Royal College of Physicians and Surgeons of Canada lists individual psychiatrists with Royal College designation of geriatric psychiatrists along with current location of psychiatrists. ${ }^{(18)} \mathrm{We}$ used this information to cross-reference with our list of geriatric psychiatrists identified by contacting academic psychiatry programs and communitybased Seniors Mental Health (SMH) programs in Ontario. We also requested information from known programs regarding other clinical programs (e.g., snowball sampling) to identify all SMH programs in Ontario.

We recorded the primary practice location for identified geriatric psychiatrists, using the information provided by the academic and SMH programs. If location information was unclear for an individual physician, we used the CPSO registration information for practice location. ${ }^{(14)}$ Each practice location was then aligned with its respective LHIN. ${ }^{(15)}$

We then determined the clinical full-time equivalent (CFTE) for each geriatric psychiatrist. Clinical and administrative leads for each program were asked to provide the total amount of time that each geriatric psychiatrist worked within a clinical program (including direct and indirect clinical care), and then to specify the total amount of time spent in the clinical program.

Many geriatric psychiatrists have some degree of clinical and educational activities; therefore, we only reduced the FTE of geriatric psychiatrists if more than $20 \%$ of their time was spent in academic and leadership activities (i.e., teaching, research, or administrative time). Where time spent on non-patient care activities was less than $20 \%$ of total time, the geriatric psychiatrist was counted as 1.0 clinical FTE.

We calculated the number of geriatric psychiatrists required in the LHIN based on the ratio of 1 geriatric psychiatrist per 10,000 aged 65 and over ${ }^{(10)}$ and the 2016 census population data. We repeated these calculations with the projected 2025 population. . $^{(10,15,16)}$

From the list of geriatric psychiatrists in 2018, we calculated the approximate current CFTE supply of geriatric psychiatrists in each LHIN (similar to the method used for geriatric medicine).

We estimated the number of geriatric psychiatry training positions available in 2017-2018 using the CAPERS Census. ${ }^{(12)} \mathrm{A}$ total of 19 positions were available in Canada in 2017-2018. The total number of PGY-5 graduates each year can significantly fluctuate, so the total number of current positions of 19 was used in this calculation. We did not average over multiple years as there has been significant growth in the number of positions over the past five years. We estimated that $40 \%$ or 8 of these trainees per year, between 2018 and 2025, 
might practice in Ontario, for a total of 64 in the province. From the 2018 number of geriatric psychiatrists in each LHIN, we subtracted the estimated number of retirements between 2018 and 2025 to arrive at an approximate total geriatric psychiatrist complement by 2025 .

\section{Care of the Elderly (COE) Physicians}

Care of the Elderly trained family physicians who have completed a recognized COE Training Program hold a certificate of added competence in Family Medicine in COE. In Canada, since 2017, COE physicians attain a designation recognizing their formal training or by attestation recognizing their past experience and practice. Of the over $300 \mathrm{COE}$ physicians in Canada, we anticipated that most were engaged in regular family practice without a special focus on frail seniors. Based on the earlier national study, the number of COE physicians trained in Canada per year has fluctuated from 9 in 2009/10 to 24 in 2015/16 and 16 in 2017/18. ${ }^{(11,12)}$

\section{Care of the Elderly (COE) Physicians Methodology}

We grouped the COE physicians into four broad categories based on the types of existing practice in relation to SGS: Direct Support, Indirect Support, Family Health Team-based (FHT)/Primary Care Collaborative Memory Clinic (recently renamed Multidisciplinary Interprofessional Network Team (MINT)), or Family Health Team/General Practice.

1. Direct Support-COE physicians who are directly employed within SGS. These direct support roles include attending/Most Responsible Physician (MRP) for a Geriatric Rehabilitation Unit (GRU), Acute Care for the Elderly (ACE) unit, Day Hospital, Acute Care inpatient consultation services, outpatient clinics or Geriatric Outreach team.

2. Indirect Support-COE physicians who work in indirect roles supporting SGS. These include attending as a hospitalist in acute care on Sub-Acute Medicine Units (SAMUs), attending on complex continuing care units or as a medical director for one or more long-term care/ nursing homes.

3. FHT/ MINT. Some COE physicians work within their own Family Health Team (FHT) but also support a Primary Care Collaborative Memory/MINT clinic role, the latter of which is a model specific to Ontario and developed by Dr. Linda Lee. ${ }^{(19)}$

4. FHT/General Practice. Most COE physicians work in an FHT or other family/general practice but with all ages of patients. We identified all COE physicians by training or attestation in the province using the College of Family Physicians (CFPC) of Canada website. ${ }^{(20)}$ This was timeconsuming, and required line-by-line review of more than 15,000 family medicine physician records on the CFPC register to locate those with the $\mathrm{COE}$ designation.

We confirmed with geriatric leaders and administrative leads in each LHIN the names of the COE physicians practising within SGS, their full-time/part-time status, and the nature of their roles within SGS, according to the four groupings outlined above. Using the CAPERS census and the five-year average (2014-2018), we calculated there are approximately $8 \mathrm{COE}$ trainees per year in Ontario. We estimate there will be 64 new trainees during the time period 2018 to 2025 added to existing 2018 number of COE physicians in each LHIN. We subtracted potential retirements 2018 to 2025 to arrive at an estimated COE physician complement by 2025 .

\section{RESULTS}

Tables 1 and 2 for Geriatricians and 3 and 4 for Geriatric Psychiatrists show the 2018 population, the 2025 projected population, the estimated need, current resource, possible retirements, recruitment needed, and estimated trainees.

Table 5 shows the COE physicians in the 14 LHINS, the current 2018 resource by direct or indirect connection to SGS, MINT, regular family practice, and possible retirements.

There is a deficit of geriatricians and geriatric psychiatrists (geriatricians: CFTE deficit of 150.5; geriatric psychiatrists: CFTE deficit of 116.3). In 2025, the projected CFTE deficit of geriatricians will increase to at least 210.35 and geriatric psychiatrists to 194.6 . Only about $30 \%$ of COE physicians work in direct support of specialized services for the elderly.

\section{DISCUSSION}

Our analyses demonstrate that both the 2018 physician complements (i.e., total number of physicians and CFTE complement) are below the recommended ratio for geriatrician and geriatric psychiatrist human resources in all LHINS with the exception of LHIN 7 (Toronto Central).

However, when the five LHINS that are served by the greater metro Toronto region are combined, the number and CFTEs are below the recommended ratios for geriatricians and geriatric psychiatrists (Tables 6 and 7).

Projecting to 2025 for Ontario, these shortfalls in total numbers of specialists are estimated to increase for Geriatric Medicine from 150.5 to 210.35 and for geriatric psychiatry from 116.3 to 194.6. The projected CFTE shortfall by 2025 is anticipated to be even greater. Uncertainty about where new trainees will practice, whether they will work full or parttime, and the proportion of their role that will be dedicated to clinical, academic or leadership roles can worsen the deficit

The projected ratio of geriatricians and geriatric psychiatrists to population could improve if more than $40 \%$ of Canadian trainees chose to practice in Ontario, recruitment of specialists increases from other provinces and overseas, and/or existing specialists postpone retirement. Future health service regions, including newly introduced Ontario Health Teams, may experience actual physician supply differently than predicted as the recruitment and/or engagement of new trainees and specialists is uncertain. Regions that recognize the need for specialist geriatricians, geriatric psychiatrists and/or 
BORRIE: ONTARIO GERIATRIC SPECIALIST PHYSICIAN RESOURCES 2018

TABLE 1.

Current number and clinical FTE of geriatricians in Ontario 2016/2018

\begin{tabular}{|c|c|c|c|c|c|c|}
\hline LHIN No. \& Name & $\begin{array}{c}\text { Population } 65+ \\
2016^{(16)}\end{array}$ & $\begin{array}{c}\text { Clinical FTE } \\
\text { Needed }^{a} 2016\end{array}$ & $\begin{array}{c}\text { Number of } \\
\text { Geriatricians } 2018\end{array}$ & $\begin{array}{c}\text { Geriatrician } \\
\text { Clinical FTE } 2018\end{array}$ & $\begin{array}{l}\text { Supply } \\
2018^{b}\end{array}$ & $\begin{array}{c}\text { Supply } \\
(\%)\end{array}$ \\
\hline 1. Erie St. Clair & 119,185 & 14 & 4 & 4 & -10 & -71.4 \\
\hline 2. South West ${ }^{\mathrm{c}}$ & 179,525 & 21.1 & 11 & 6.9 & -14.2 & -67.3 \\
\hline 3. Waterloo Wellington & 113,425 & 13.3 & 6 & 5 & -8.3 & -62.4 \\
\hline 4. Hamilton Niagara Haldimand Brant ${ }^{\mathrm{c}}$ & 268,025 & 31.5 & 18 & 12.9 & -18.6 & -59.0 \\
\hline 5. Central West & 116,205 & 13.7 & 6 & 4.4 & -9.3 & -67.9 \\
\hline 6. Mississauga Halton & 163,810 & 19.2 & 17 & 14.8 & -4.4 & -22.9 \\
\hline 7. Toronto Central ${ }^{\mathrm{c}}$ & 172280 & 20.2 & 40 & 22.8 & 2.6 & 12.9 \\
\hline 8. Central & 278,800 & 32.8 & 17 & 16.5 & -16.3 & -49.7 \\
\hline 9. Central East & 270,200 & 31.7 & 6 & 5.7 & -26 & -82.0 \\
\hline 10. South East $\mathrm{t}^{\mathrm{c}}$ & 107,110 & 12.6 & 3 & 2.55 & -10.05 & -79.8 \\
\hline 11. Champlain ${ }^{\mathrm{c}}$ & 215,410 & 25.3 & 15 & 9.1 & -16.2 & -64.0 \\
\hline 12. North Simcoe Muskoka & 90,835 & 10.7 & 4 & 4 & -6.7 & -62.6 \\
\hline 13. North East $\mathrm{t}^{\mathrm{c}}$ & 113,760 & 13.4 & 3 & 2.3 & -11.1 & -82.8 \\
\hline 14. North West & 41,310 & 4.9 & 3 & 3 & -1.9 & -38.8 \\
\hline TOTAL & $2,249,880$ & 264.4 & 153 & 113.95 & -150.5 & \\
\hline
\end{tabular}

${ }^{\mathrm{a} C a l c u l a t e d}$ 1.175 FTE required per 10,000 pop $65+$.

${ }^{\mathrm{b}}$ Based on Need minus CFTE.

${ }^{\mathrm{c}}$ Medical Schools AHSC.

CFTE $=$ clinical full-time equivalent

TABLE 2.

Projected need and future geriatrician estimates (2025)

\begin{tabular}{|c|c|c|c|c|c|c|}
\hline LHIN No. \& Name & $\begin{array}{c}\text { Population } \\
65+2025\end{array}$ & $\begin{array}{l}\text { Clinical FTE } \\
\text { Needed }^{a} 2025\end{array}$ & $\begin{array}{c}\text { Geriatrician } \\
\text { Clinical FTE } 2018\end{array}$ & $\begin{array}{c}\text { Possible } \\
\text { Retirements }^{b} 2025\end{array}$ & $\begin{array}{l}\text { Recruitment } \\
\text { Needed }^{c} 2025\end{array}$ & $\begin{array}{c}\text { Estimated Trainees } \\
2018-2025\end{array}$ \\
\hline 1. Erie St. Clair & 160,602 & 18.9 & 4 & 1 & 15.9 & \\
\hline 2. South West $\mathrm{e}^{\mathrm{e}}$ & 245,493 & 28.8 & 6.9 & 1 & 22.9 & \\
\hline 3. Waterloo Wellington & 165,625 & 19.5 & 5 & 0 & 14.5 & \\
\hline $\begin{array}{l}\text { 4. Hamilton Niagara } \\
\text { Haldimand Brant } \mathrm{e}^{\mathrm{e}}\end{array}$ & 366,656 & 43.1 & 12.9 & 2 & 32.2 & \\
\hline 5. Central West & 176,840 & 20.8 & 4.4 & 1 & 17.4 & \\
\hline 6. Mississauga Halton & 258,062 & 30.3 & 14.8 & 5 & 20.5 & \\
\hline 7. Toronto Central ${ }^{\mathrm{e}}$ & 267,907 & 31.5 & 22.8 & 11 & 19.7 & \\
\hline 8. Central & 409,850 & 48.2 & 16.5 & 4 & 35.7 & \\
\hline 9. Central East & 368,304 & 43.3 & 5.7 & 4 & 41.6 & \\
\hline 10. South East ${ }^{\mathrm{e}}$ & 142,253 & 16.7 & 2.55 & 1 & 15.15 & \\
\hline 11. Champlain ${ }^{\mathrm{e}}$ & 307,307 & 36.1 & 9.1 & 5 & 32 & \\
\hline 12. North Simcoe Muskoka & 131,451 & 15.4 & 4 & 1 & 12.4 & \\
\hline 13. North East ${ }^{\mathrm{e}}$ & 146,736 & 17.2 & 2.3 & 0 & 14.9 & \\
\hline 14. North West & 55,404 & 6.5 & 3 & 0 & 3.5 & \\
\hline \multirow[t]{2}{*}{ TOTAL } & $3,202,490$ & 376.3 & 113.95 & 36 & 298.35 & $88^{f}$ \\
\hline & & & & & $\begin{array}{l}\text { Estimated } \\
2025 \text { Deficit: }\end{array}$ & -210.35 \\
\hline
\end{tabular}

${ }^{a}$ Assumes 1.175 FTE required per 10,000 pop 65+.

${ }^{\mathrm{b}}$ Retirement Based on Year of Medical Degree +40 .

${ }^{\mathrm{c}}$ Recruitment need based on Needed minus Current Resource plus Possible retirements.

${ }^{\mathrm{d}}$ Estimated newly trained geriatricians. CAPERS Census PGY-5 geriatric fellows: 2014-2018 average 27.5/yr. (For estimation purposes we assume 40\% will be employed in Ontario); 11/year $\times 8$ years $=88(2018-25)$; assumes all new recruits will be FTE. (No assumptions about movement of geriatricians from Ontario or recruitment from outside of Canada or overseas).

eMedical Schools AHSC.

fWe don't know where new trainees will practice in the province. 
BORRIE: ONTARIO GERIATRIC SPECIALIST PHYSICIAN RESOURCES 2018

TABLE 3.

Current number and clinical FTE of geriatric psychiatrists in Ontario 2016/2018

\begin{tabular}{|c|c|c|c|c|c|c|}
\hline LHIN No. \& Name & $\begin{array}{l}\text { Population } \\
65+(16) 2016\end{array}$ & $\begin{array}{c}\text { Clinical FTE } \\
\text { Needed }^{a} 2016\end{array}$ & $\begin{array}{c}\text { Number of } \\
\text { Geriatric } \\
\text { Psychiatrists } 2018\end{array}$ & $\begin{array}{c}\text { Geriatric } \\
\text { Psychiatrist CFTE } \\
2018\end{array}$ & $\begin{array}{l}\text { Supply } \\
2018^{b}\end{array}$ & $\begin{array}{c}\text { Supply } \\
(\%)\end{array}$ \\
\hline 1. Erie St. Clair & 119,185 & 11.9 & 2 & 1 & -10.9 & -91.6 \\
\hline 2. South West ${ }^{\mathrm{c}}$ & 179,525 & 18 & 11 & 10.4 & -7.6 & -42.2 \\
\hline 3. Waterloo Wellington & 113,425 & 11.3 & 5 & 5.2 & -6.1 & -54.0 \\
\hline 4. Hamilton Niagara Haldimand Brant ${ }^{\mathrm{c}}$ & 268,025 & 26.8 & 10 & 6.2 & -20.6 & -76.9 \\
\hline 5. Central West & 116,205 & 11.6 & 3 & 3.6 & -8 & -69.0 \\
\hline 6. Mississauga Halton & 163,810 & 16.4 & 8 & 4.6 & -11.8 & -72 \\
\hline 7. Toronto Central ${ }^{\mathrm{c}}$ & 172,280 & 17.2 & 65 & 31.2 & 14 & 81.4 \\
\hline 8. Central & 278,800 & 27.9 & 7 & 3.8 & -24.1 & -86.4 \\
\hline 9. Central East & 270,200 & 27 & 13 & 8 & -19 & -70.4 \\
\hline 10. South East ${ }^{\mathrm{c}}$ & 107,110 & 10.7 & 8 & 5.1 & -5.6 & -52.3 \\
\hline 11. Champlain ${ }^{\mathrm{c}}$ & 215,410 & 21.5 & 23 & 20.9 & -0.6 & -2.8 \\
\hline 12. North Simcoe Muskoka & 90,835 & 9.1 & 4 & 4.8 & -4.3 & -47.3 \\
\hline 13. North East ${ }^{\mathrm{c}}$ & 113,760 & 11.4 & 5 & 2.3 & -9.1 & -79.8 \\
\hline 14. North West & 41,310 & 4.1 & 2 & 1.5 & -2.6 & -63.4 \\
\hline TOTAL & $2,249,880$ & 224.9 & 166 & 108.6 & -116.3 & $-51.7 \%$ \\
\hline
\end{tabular}

${ }^{\mathrm{a} C a l c u l a t e d}$ 1.0 CFTE required per 10,000 pop $65+$.

${ }^{b}$ Based on Need minus CFTE.

${ }^{\mathrm{c}}$ Medical Schools AHSC.

$\mathrm{CFTE}=$ clinical full-time equivalent

TABLE 4.

Geriatric psychiatrists in Ontario future projection of clinical full-time equivalents

\begin{tabular}{|c|c|c|c|c|c|c|}
\hline LHIN No. \& Name & $\begin{array}{c}\text { Population } 65+ \\
2025\end{array}$ & $\begin{array}{l}\text { Clinical FTE } \\
\text { Needed }^{a} 2025\end{array}$ & $\begin{array}{c}\text { Geriatric Psychiatrist } \\
\text { CFTE } 2018\end{array}$ & $\begin{array}{c}\text { Possible } \\
\text { Retirement }^{b} 2025\end{array}$ & $\begin{array}{l}\text { Recruitment } \\
\text { Needed }^{c} 2025\end{array}$ & $\begin{array}{l}\text { Estimated } \\
\text { Trainees }^{d}\end{array}$ \\
\hline 1. Erie St. Clair & 160,602 & 16.1 & 1 & 0 & 15.1 & \\
\hline 2. South West $\mathrm{t}^{\mathrm{e}}$ & 245,493 & 24.5 & 10.4 & 2 & 16.1 & \\
\hline 3. Waterloo Wellington & 165,625 & 16.6 & 5.2 & 1 & 12.4 & \\
\hline $\begin{array}{l}\text { 4. Hamilton Niagara } \\
\text { Haldimand Brant }{ }^{\mathrm{e}}\end{array}$ & 366,656 & 36.7 & 6.2 & 3 & 33.5 & \\
\hline 5. Central West & 176,840 & 17.7 & 3.6 & 1 & 15.1 & \\
\hline 6. Mississauga Halton & 258,062 & 25.8 & 4.6 & 2 & 23.2 & \\
\hline 7. Toronto Central ${ }^{\mathrm{e}}$ & 267,907 & 26.8 & 31.2 & 20 & 15.6 & \\
\hline 8. Central & 409,850 & 41 & 3.8 & 2 & 39.2 & \\
\hline 9. Central East & 368,304 & 36.8 & 8 & 4 & 32.8 & \\
\hline 10. South East $\mathrm{e}^{\mathrm{e}}$ & 142,253 & 14.2 & 5.1 & 3 & 12.1 & \\
\hline 11. Champlain ${ }^{\mathrm{e}}$ & 307,307 & 30.7 & 20.9 & 7 & 16.8 & \\
\hline 12. North Simcoe Muskoka & 131,451 & 13.1 & 4.8 & 1 & 9.3 & \\
\hline 13. North East ${ }^{\mathrm{e}}$ & 146,736 & 14.7 & 2.3 & 1 & 13.4 & \\
\hline 14. North West & 55,404 & 5.5 & 1.5 & 0 & 4 & \\
\hline \multirow[t]{2}{*}{ TOTAL } & $3,202,490$ & 320.2 & 108.6 & 47 & 258.6 & $64^{\mathrm{f}}$ \\
\hline & & & & & $\begin{array}{l}\text { Estimated } 2025 \\
\text { Deficit: }\end{array}$ & 194.6 \\
\hline
\end{tabular}

aAssumes 1.0 FTE required per 10,000 65+.

${ }^{\mathrm{b}}$ Based on Year of Graduation +40 .

${ }^{\mathrm{c}}$ Based on needed minus current.

In Canada, there are 22 geriatric psychiatry residency positions per year. For estimation purposes, we assume $40 \%$ will find work in Ontario. $19 \times 0.4$

$=7.6 .8$ Trainees per year $\times 8$ years $=64$ trainees.

${ }^{\mathrm{e}}$ Medical Schools AHSC.

fWe don't know where new trainees will practice in the province. 


\section{BORRIE: ONTARIO GERIATRIC SPECIALIST PHYSICIAN RESOURCES 2018}

specialized geriatric team resources may actively create human resource plans to address these needs. As a consequence, recruitment strategies may have success in attracting newly trained specialists to underserved regions. The number of COE physicians varies between the 14 LHINs in no apparent pattern of distribution. COE physician complements also vary between LHINs as to the proportions that are employed directly and indirectly to support SGS.

In LHIN 11 (Champlain), 16 of 25 COE physicians support SGS. In contrast, none of the 7 COE physicians in LHIN
3 (Waterloo Wellington) and only one of 8 in LHIN 9 (Central East) support SGS.

A barrier to engaging COE physicians for direct support within SGS is an absence of an appropriate remuneration system. There are no specific COE Ontario Health Insurance Plan(OHIP) billing codes. There are only a few COE positions funded by Alternate Payment Plans (APPs) or novel local funding mechanisms that support the intensive clinical direct and indirect time needed to assess and manage older adults with complex health concerns (including frailty or mental health and/or substance use issues).

TABLE 5.

Care of the elderly physicians (COE) in Ontario current state 2018

\begin{tabular}{|c|c|c|c|c|c|c|}
\hline LHIN No. \& Name & $\begin{array}{c}\text { Number of } \\
\text { COE MDs } \\
2018\end{array}$ & $\begin{array}{c}\text { SGS Direct } \\
\text { Support Role }^{a}\end{array}$ & $\begin{array}{c}\text { SGS Indirect } \\
\text { Supporting Role }^{b}\end{array}$ & $\begin{array}{l}\text { Family Health Team/ } \\
\text { Primary Care } \\
\text { Memory Clinic Role }\end{array}$ & $\begin{array}{c}\text { Regular Family } \\
\text { Practicel }^{\text {FHT Role }}\end{array}$ & $\begin{array}{c}\text { Possible Number } \\
\text { of Retirements } \\
2025\end{array}$ \\
\hline 1. Erie St. Clair & 6 & 0.2 & 0 & 0.5 & 5.3 & 1 \\
\hline 2. South West ${ }^{\mathrm{e}}$ & 9 & 0.2 & 1.5 & 0.5 & 6.8 & 0 \\
\hline 3. Waterloo Wellington & 7 & 0 & 0 & 3 & 4 & 0 \\
\hline $\begin{array}{l}\text { 4. Hamilton Niagara } \\
\text { Haldimand Brant }{ }^{\mathrm{e}}\end{array}$ & 13 & 1 & 2 & $\mathrm{~N} / \mathrm{A}$ & $\mathrm{N} / \mathrm{A}$ & 1 \\
\hline 5. Central West & 5 & 1 & 0 & 0 & 4 & 0 \\
\hline 6. Mississauga Halton & 6 & 0 & 3 & 0 & 3 & 0 \\
\hline 7. Toronto Central ${ }^{\mathrm{e}}$ & 23 & 4 & $\mathrm{~N} / \mathrm{A}$ & $\mathrm{N} / \mathrm{A}$ & N/A & 2 \\
\hline 8. Central & 16 & 4.6 & 2 & 0 & 8 & 2 \\
\hline 9. Central East & 8 & 0 & 1 & N/A & 3.5 & 2 \\
\hline 10. South East ${ }^{\mathrm{e}}$ & 7 & 3.6 & 0.4 & 0 & 3 & 0 \\
\hline 11. Champlain ${ }^{\mathrm{e}}$ & 25 & 11 & 5 & 0 & 9 & 1 \\
\hline $\begin{array}{l}\text { 12. North Simcoe } \\
\text { Muskoka }\end{array}$ & 5 & 0.5 & 1 & 0.5 & 3 & 2 \\
\hline 13. North East $\mathrm{e}^{\mathrm{e}}$ & 12 & 3.2 & 0.5 & 0 & 8.3 & 1 \\
\hline 14. North West & 1 & 0.75 & 0 & 0 & 0.25 & 0 \\
\hline TOTAL & 143 & 30.05 & 16.4 & 4.5 & 58.15 & 12 \\
\hline
\end{tabular}

${ }^{a}$ Directly employed in Specialized Geriatric Services (e.g., attending/MRP on a GRU or ACE unit, Day Hospital, outpatient or outreach assessments). bIndirect role supporting SGS (e.g., hospitalist in acute care sub-acute medicine unit (SAMU), attending on a complex continuing care unit, medical director for one or more long-term care /nursing homes).

${ }^{c}$ Working in a Family Health Team or community health centre setting and Primary Care Collaborative Memory Clinic.

dWorking in a Family Health Team, other family/general practice but with all ages or a focused practice

eMedical School AHSC

$\mathrm{N} / \mathrm{A}=$ limited response from COE office.

TABLE 6.

Current state of geriatricians Greater Toronto Area (GTA) LHINS

\begin{tabular}{|c|c|c|c|c|c|c|}
\hline LHIN No. \& Name & $\begin{array}{c}\text { Population } 65+ \\
2016^{a}\end{array}$ & $\begin{array}{l}\text { Clinical FTE } \\
\text { Needed }^{b} 2016\end{array}$ & $\begin{array}{c}\text { Number of } \\
\text { Geriatricians } 2018\end{array}$ & $\begin{array}{c}\text { Geriatrician CFTE } \\
2018\end{array}$ & Supply $2018^{c}$ & Supply $(\%)$ \\
\hline 5. Central West & 116,205 & 13.7 & 6 & 4.4 & -9.3 & -68 \\
\hline 6. Mississauga Halton & 163,810 & 19.2 & 17 & 14.8 & -4.4 & -23 \\
\hline 7. Toronto Central & 172280 & 20.2 & 41 & 22.8 & 2.6 & 13 \\
\hline 8. Central & 278,800 & 32.8 & 17 & 16.5 & -16.3 & -50 \\
\hline 9. Central East & 270,200 & 31.7 & 7 & 5.7 & -26 & -82 \\
\hline TOTAL & $1,001,295$ & 117.6 & 88 & 64.2 & -53.4 & \\
\hline
\end{tabular}

aAssumes 1.175 FTE required per 10, $00065+$.

${ }^{b}$ Based on Year of Graduation +40 .

${ }^{\mathrm{c}}$ Based on needed minus current. 
TABLE 7.

Current state of geriatric psychiatrists Greater Toronto area (GTA) LHINS

\begin{tabular}{lccccc}
\hline LHIN No. \& Name & $\begin{array}{c}\text { Population 65+ } \\
2016^{a}\end{array}$ & $\begin{array}{c}\text { Clinical FTE } \\
\text { Needed }^{b} \text { 2016 }\end{array}$ & $\begin{array}{c}\text { Number of } \\
\text { Geriatricians 2018 }\end{array}$ & $\begin{array}{c}\text { Geriatrician CFTE } \\
\text { 2018 }\end{array}$ & $\begin{array}{c}\text { Supply 2018c } \\
\text { Supply (\%) }\end{array}$ \\
\hline 5. Central West & 116,205 & 11.6 & 3 & 3.6 & -8 \\
6. Mississauga Halton & 163,810 & 16.4 & 8 & 4.6 & -69.0 \\
7. Toronto Central & 172,280 & 17.2 & 65 & 31.2 & -11.8 \\
8. Central & 278,800 & 27.9 & 7 & 3.8 & 14 \\
9. Central East & 270,200 & 27 & 13 & 8 & -24.1 \\
TOTAL & $1,001,295$ & 100.1 & 96 & 51.2 & -19 \\
\end{tabular}

${ }^{\mathrm{a}}$ Assumes 1.0 FTE required per 10, $00065+$.

${ }^{b}$ Based on Year of Graduation +40 .

${ }^{\mathrm{c}}$ Based on needed minus current.

Some LHINs, including LHIN 11 (Champlain), LHIN 8 (Central), LHIN 10 (South East), and LHIN 13 (Northeast), have been successful in negotiating local funding arrangements and APPs to attract and retain COE physicians. This has increased the overall physician complement available to work with specialized teams, reducing the impact of the relative undersupply of specialists in these regions.

There are several reasons to explain the geographic concentration of geriatric specialists within LHIN 7 (Toronto Central). LHIN 7 includes the largest medical school and affiliated AHSCs in the province and the country. The medical school and associated AHSCs are responsible for training the largest number of medical students, residents, and subspecialty residents in Canada.

Existing LHIN 7 geriatric specialists reported that they routinely provide clinical consultation not only for patients within their own LHIN but also to several surrounding LHIN regions (e.g., Central East, Central, Central West, and Mississauga). The Toronto Central LHIN 7 also reported the region experiences significant patient inflows for convenience or because of expertise found within this LHIN.

\section{Limitations-Geriatricians \& Geriatric Psychiatrists}

Because the total number of current geriatricians and geriatric psychiatrists is small in most LHINs, any recruitment to a LHIN or loss from a LHIN will affect the supply, number, and proportion needed in relationship to the ratio in each LHIN. We believe that the current number of geriatricians and geriatric psychiatrists in 2018 are accurate and are clearly below the two ratios we used to estimate the numbers of specialists required. The CFTE complement was challenging to confirm and, when the CFTE was unknown, we assumed the specialist was working as a 1.0 CFTE. For this reason, we are more likely to have overestimated rather than underestimated the CFTEs available for direct and indirect clinical consultation. We used the 2016 Statistics Canada Census population numbers for the denominator of the ratio, but the 2018 census for known number of specialists. This will have understated the number of specialists needed in 2018 as the 2018 population over 65 was larger than in 2016, and published 2018 census data were not available.

\section{Limitations-Care of the Elderly (COE) Physicians}

Due to staffing changes and, in some cases, large catchment areas, we learned that community leads and local contacts are not always aware of COE physicians practising in their geographical area, or the extent they are supporting SGS. It is possible that we have underestimated the direct and indirect contribution of COE physicians to SGS.

Some COE physicians identified by LHIN leads or support staff do not have "official" COE designation. These physicians are not included in the final count, which may also understate the current number of COEs or equivalents supporting SGS. Our review did not address the number of geriatric-focused practice primary care physicians, whose impact on the care of older people living with frailty is, as yet, unmeasured.

\section{CONCLUSION}

We have no doubt there is significant undersupply in the number of geriatricians, geriatric psychiatrists, and $\mathrm{COE}$ physicians required to meet current and anticipated need. At present, across Ontario, many Ontario Health Team applicants have identified older adults living with frailty as a population of focus. ${ }^{(5)}$ How geriatric specialists and geriatric interdisciplinary teams will be engaged within Ontario Health Teams is, as yet, unclear. What is clear is the pressing societal need to expand training and clinical positions to ensure sufficient future specialists in geriatric medicine, geriatric psychiatry, and family physicians in Care of the Elderly. Concurrently, there is an emphasis on regional planning and integration of all three medical disciplines within SGS for greater efficiencies. Discussions, led by the PGLO, are ongoing and will identify opportunities for the three medical disciplines to work synergistically within specialized interprofessional geriatric teams.

National efforts by the Canadian Geriatrics Society to attract medical trainees to geriatric specialties and opportunities 
within SGS are having some success. These efforts can be bolstered by proven physician human resource recruitment and retention strategies, such as specialized interprofessional team practice environments, particularly in underserved regions, as well as appropriate physician funding models. Ontario Health Teams have identified older adults with complex health concerns or frailty as a population of concern. Consequently, they will require geriatric specialists and SGS to support these efforts. This paper can assist with the planning of a workforce that can best meet the needs of some of Ontario's most vulnerable citizens.

\section{ACKNOWLEDGEMENTS}

The Specialized Geriatric Services Mapping Project, funded by the Ministry of Health (MOH), was administered through the Provincial Geriatrics Leadership Office (PGLO). The authors acknowledge the collaboration/assistance of Medical/Program Directors, SGS leadership and Division leads of the individual LHINs, and the PGLO with their collection of clinical full-time equivalent (CFTE) data.

\section{CONFLICT OF INTEREST DISCLOSURES}

The authors declare that no conflicts of interest exist.

\section{REFERENCES}

1. Regional Geriatrics Programs of Ontario. Specialized geriatric services in Ontario RGPO - physician human resources report. RGPs of Ontario [Internet]. [cited 2020 Mar 28]. Available from: https://www.rgps.on.ca/resources/specialized-geriatricservices-in-ontario-rgpo-physician-human-resources-report/

2. Canadian Institute for Health Information. Infographic: Canada's seniors population outlook: uncharted territory. Ottawa, ON: CIHI [Internet]. [cited 2020 Mar 28]. Available from: https://www.cihi.ca/en/infographic-canadas-seniors-population -outlook-uncharted-territory

3. Regional Geriatrics Programs of Ontario. Position statement on the need for expert clinical care for older people living with complex health condition. RGPs of Ontario [Internet]; 2019. [cited 2020 Mar 28]. Available from: https://www.rgps.on.ca/ resources/position-statement-on-the-need-for-expert-clinicalcare-for-older-people-living-with-complex-health-conditions/

4. Chang SF, Lin HC, Cheng CL. The relationship of frailty and hospitalization among older people: evidence from a metaanalysis. J Nurs Scholarsh. 2018;50(4):383-91.

5. Ministry of Health and Long-term Care. Hallway health care: a system under strain. First Interim Report from the Premier's Council on Improving Healthcare and Ending Hallway Medicine. Toronto, ON: the Ministry; 2019.

6. Tsakitzidis G, Timmermans $\mathrm{O}$, Callewaert $\mathrm{N}$, et al. Outcome indicators on interprofessional collaboration interventions for elderly. Int J Integr Care. 2016;16(2):1-17.
7. Partnership for Health in Aging Workgroup on Interdisciplinary Team Training in Geriatrics. Position statement on interdisciplinary team training in geriatrics: an essential component of quality health care for older adults. J Am Geriatr Soc. 2014;62(5):961-65.

8. Sinha SK. Living Longer, Living Well. Report submitted to the Minister of Health \& Long-Term Care and the Minister Responsible for Seniors on recommendations to Inform a Seniors Strategy for Ontario. Toronto, ON: the Ministry; 2012.

9. Fisher JM, Garside M, Hunt K, et al. Geriatric medicine workforce planning: A giant geriatric problem or has the tide turned? Clin Med. 2014;14(2):102-06.

10. Maccourt P, Wilson K, Tourigny-Rivard M-F. Guidelines for comprehensive mental health services for older adults in Canada [Internet]. Calgary, AB: Mental Health Commission; 2011 [cited 2020 Mar 28]. Available from: https:// www.mentalhealthcommission.ca/sites/default/files/2017-09/ mhcc_seniors_guidelines_0.pdf

11. Hogan D, Borrie D, Basran M, et al. Specialist Physicians in Geriatrics-Report of the Canadian Geriatrics Society Physician Resource Work Group. Can Geriatr J. [Internet]. 2012;15(3):68-79. Available from: https:/cgjonline.ca/index. $\mathrm{php} / \mathrm{cgj} /$ article/view/41/85

12. CAPER. Annual Census. Caper Annual Census of postM.D. Trainees.[Internet]. Ottawa, ON: CAPER; 2019. [cited 2020 Mar 28]. Available from: https://caper.ca/ postgraduate-medical-education/annual-census

13. Statistics Canada: Canada's national statistical agency. Population and Dwelling Counts [Internet]. [cited 2020 Mar 28]. Available from: https://www12.statcan.gc.ca/census-recensement/2016/ $\mathrm{dp}-\mathrm{pd} / \mathrm{hlt}$-fst/pd-pl/Table.cfm?Lang=Eng\&T=101\&S=50\&O=A

14. CPSO. Doctor search [Internet]. Toronto, ON: College of Physicians \& Surgeons. [cited 2020 Mar 28]. Available from: https:// doctors.cpso.on.ca/

15. Local Health Integration Network (LHIN). Ontario's LHINs [Internet]. [cited 2020 Mar 28]. Available from: http://www. lhins.on.ca/

16. Ontario Community Health Profiles Partnership (OCHPP). Home Page [Internet]. [cited 2020 Mar 28]. Available from: http://www.ontariohealthprofiles.ca/

17. Government of Ontario. Ontario Data Catalogue. Population projections/ Datasets [Internet]. [cited 2020 Mar 28]. Available from: https://data.ontario.ca/dataset/population-projections

18. The Royal College of Physicians and Surgeons of Canada. Home Page [Internet]. [cited 2020 Mar 28]. Available from: http://www.royalcollege.ca/rcsite/home-e

19. MINT Memory Clinic. Home Page [Internet]. Kitchener, ON: the Clinic. [cited 2020 Mar 28]. Available from: http:// mintmemory.ca/

20. The College of Family Physicians Canada. Home Page [Internet]. Mississauga, ON: the College. [cited 2020 Mar 28]. Available from: https://www.cfpc.ca/Home/

Correspondence to: Michael Borrie, MB ChB, FRCPC, Schulich School of Medicine \& Dentistry, Western University, 1151 Richmond St., London, ON N6A 5C1

E-mail: michael.borrie@sjhc.london.on.ca 